\title{
Septembre 2013
}

Le mois de septembre, proche des valeurs saisonnières, nous offre toutefois un début d'automne marqué par une certaine douceur. La température moyenne mensuelle sur la France a été supérieure de $0,6^{\circ} \mathrm{C}$ à la normale. Débuté très chaudement, le mois de septembre a connu ensuite des températures assez fraîches pour la saison avant que le mercure ne remonte sensiblement en fin de mois.

La pluviométrie, proche de la normale en moyenne sur la France, a été géographiquement contrastée. Inférieure à la normale sur les régions côtières, elle a été excédentaire, parfois de plus de $20 \%$, du Sud-Ouest au Bassin parisien et au Nord-Est ainsi qu'en Savoie et dans les Cévennes.

Le nombre de jours de vent fort est conforme à la normale. Les rafales de vent ont rarement dépassé $100 \mathrm{~km} / \mathrm{h}$, excepté sur le pourtour méditerranéen et la Corse.

L'ensoleillement a été conforme à la normale sur une grande partie du pays. Généreux en Provence et en Corse, il est toutefois déficitaire du nord de I'Aquitaine et de MidiPyrénées à l'̂le-de-France et à la Bourgogne.
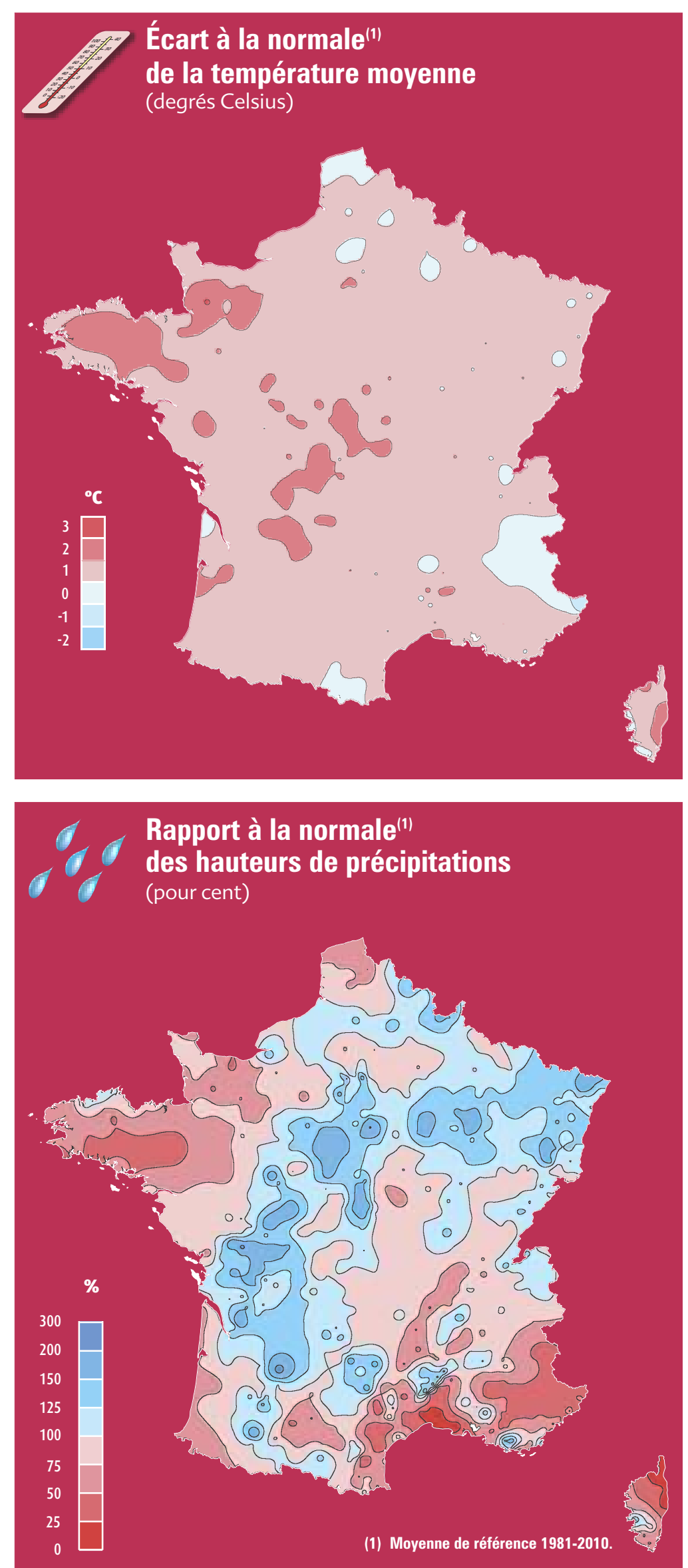


\section{Septembre 2013}
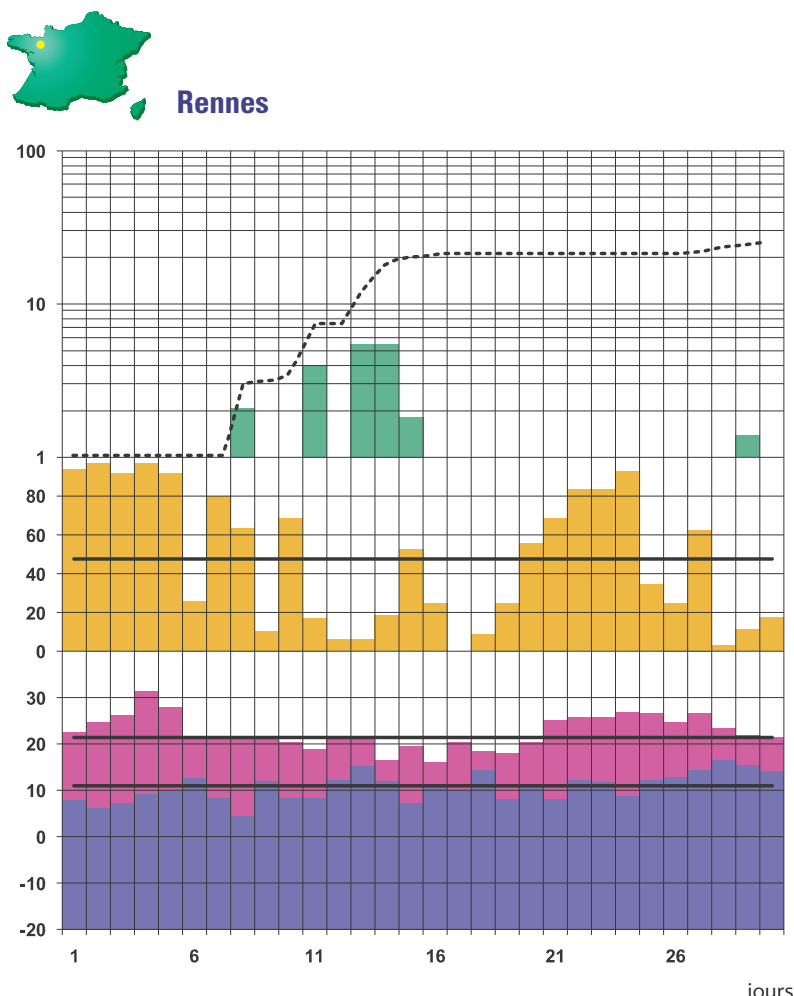

Total mensuel des précipitations : $40 \%$ de la normale

Fraction d'insolation moyenne : normale

Température moyenne : $>0,6^{\circ} \mathrm{C}$ à la normale
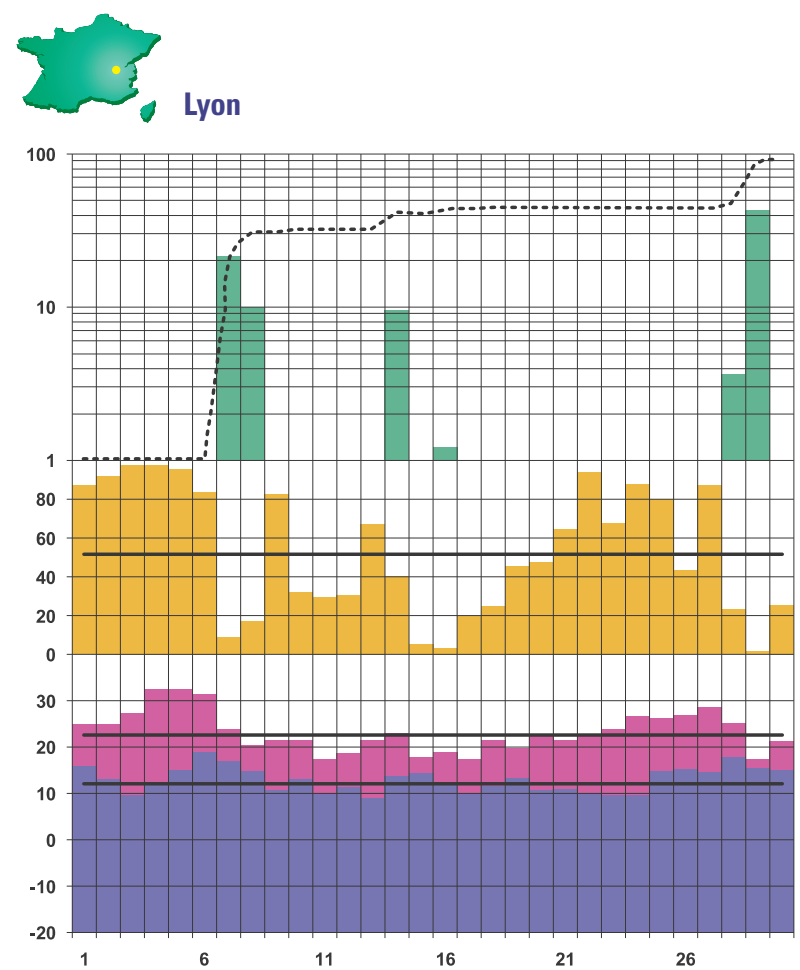

Total mensuel des précipitations : normal

Fraction d'insolation moyenne : normale

Température moyenne : $>0,9^{\circ} \mathrm{C}$ à la normale

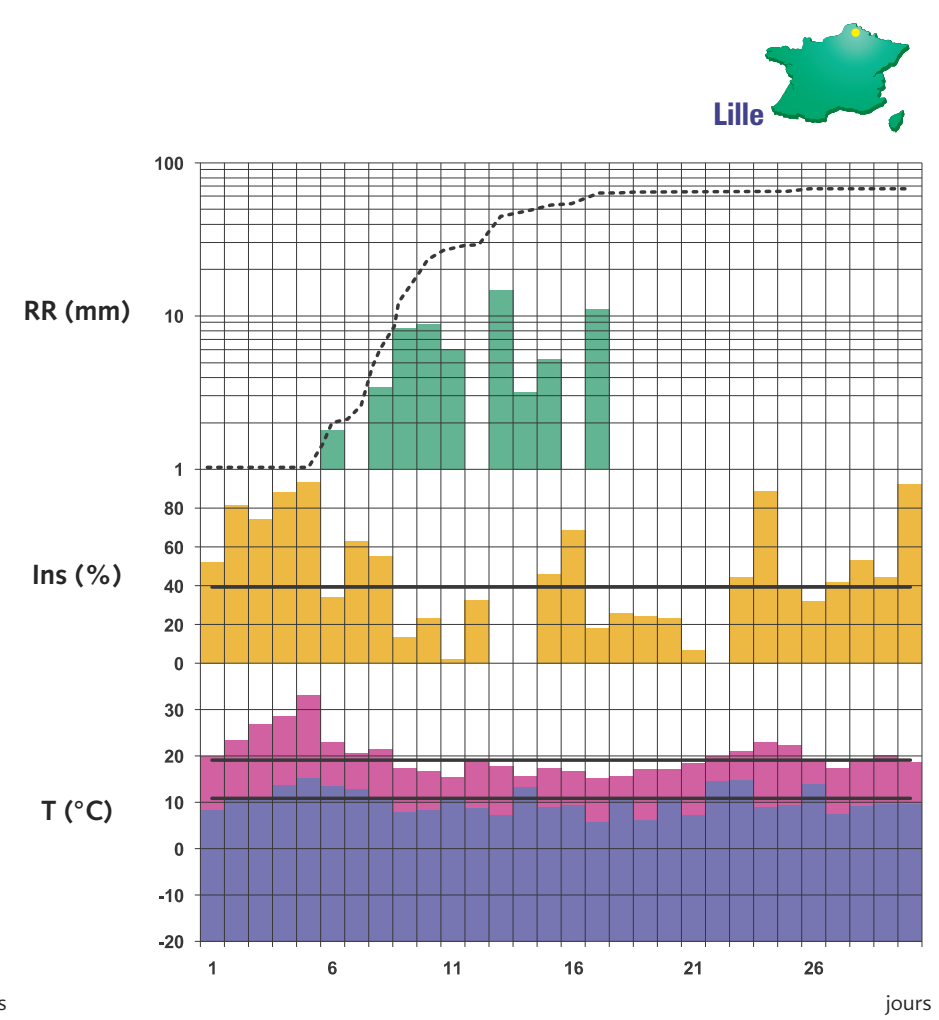

Total mensuel des précipitations : 1,1 fois la normale

Fraction d'insolation moyenne : normale

Température moyenne : $>0,1^{\circ} \mathrm{C}$ à la normale
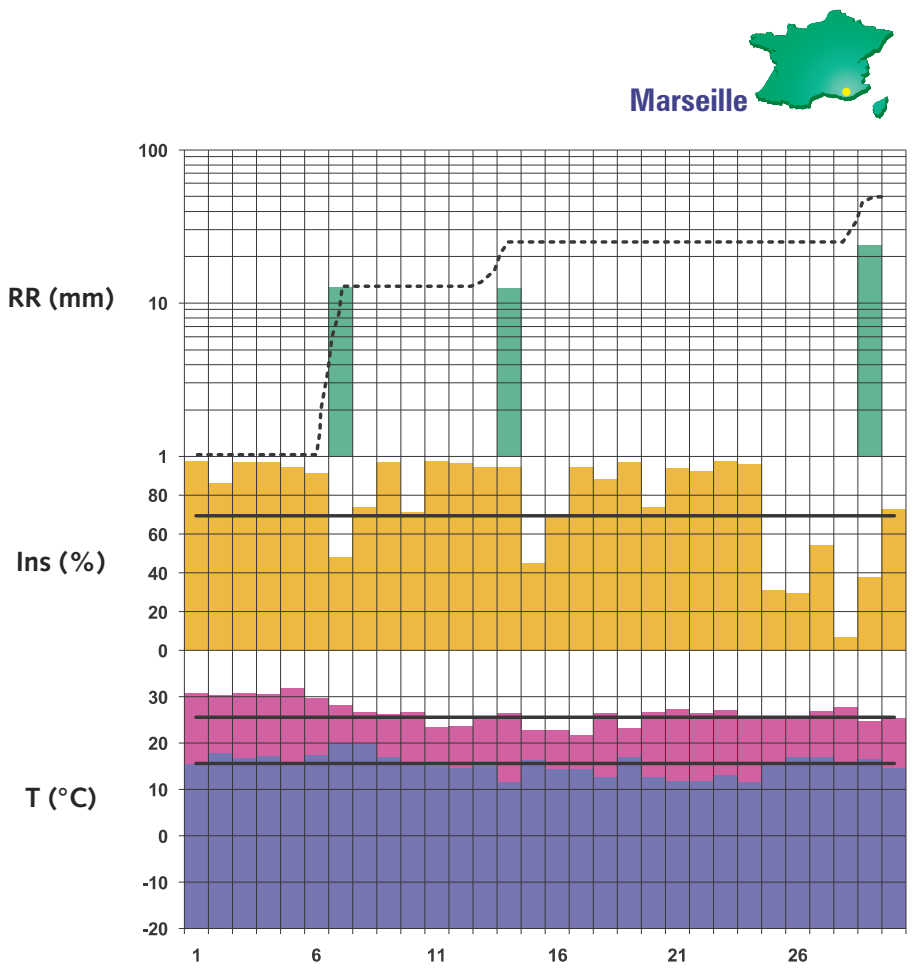

Total mensuel des précipitations : $60 \%$ de la normale

Fraction d'insolation moyenne : légèrement excédentaire

Température moyenne : $>0,5^{\circ} \mathrm{C}$ à la normale

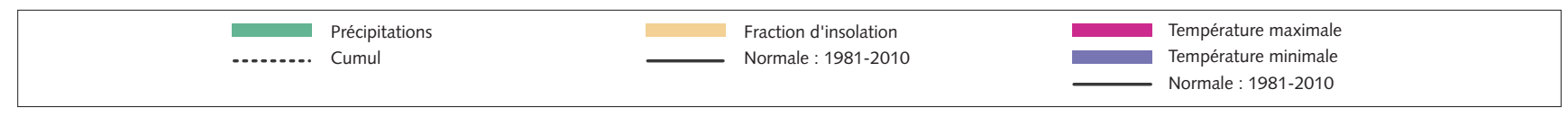




\section{Septembre 2013}
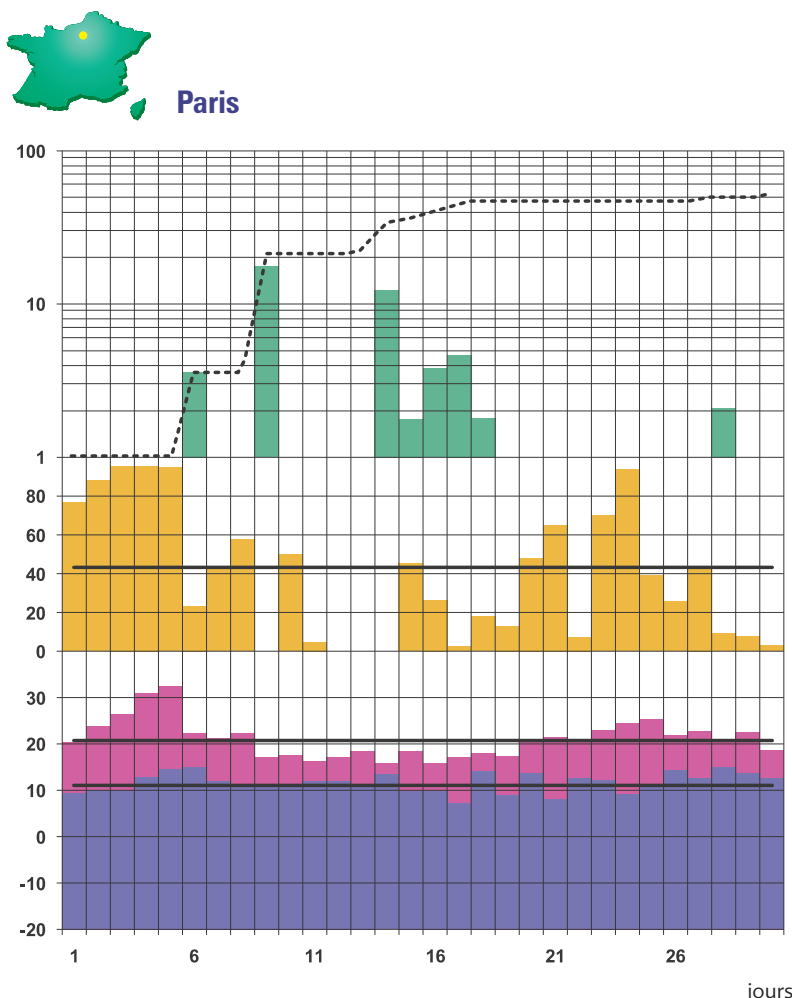

Total mensuel des précipitations : 1,1 fois la normale

Fraction d'insolation moyenne : légèrement déficitaire Température moyenne : $>0,5^{\circ} \mathrm{C}$ à la normale
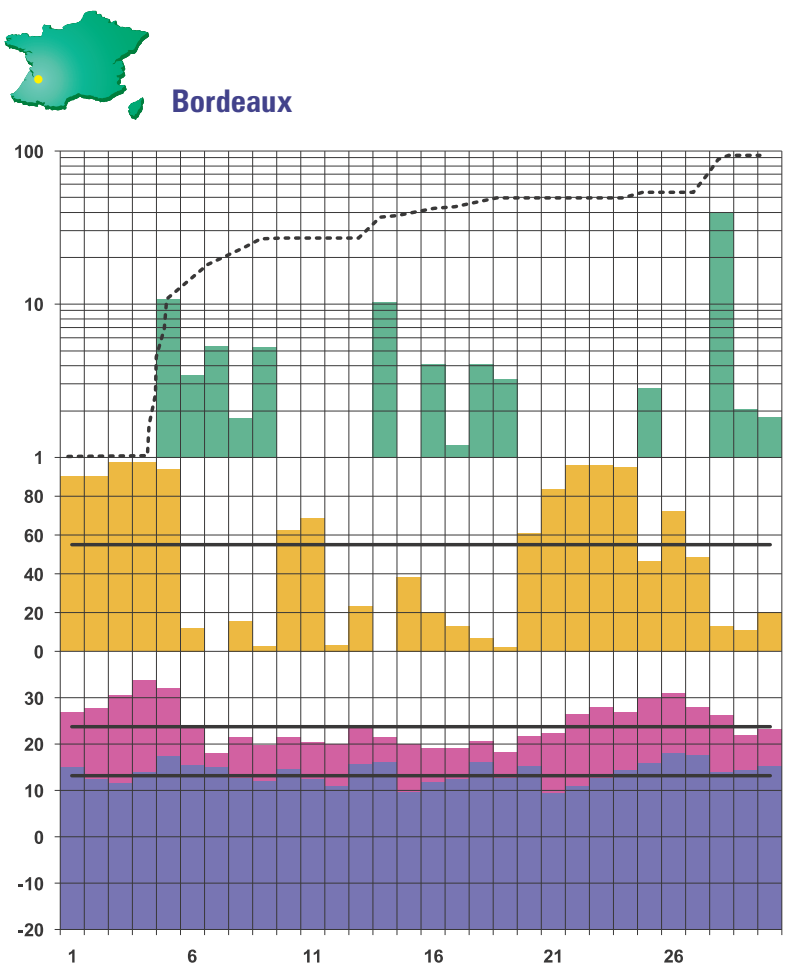

Total mensuel des précipitations : 1,1 fois la normale Fraction d'insolation moyenne : légèrement déficitaire Température moyenne : $>0,6^{\circ} \mathrm{C}$ à la normale

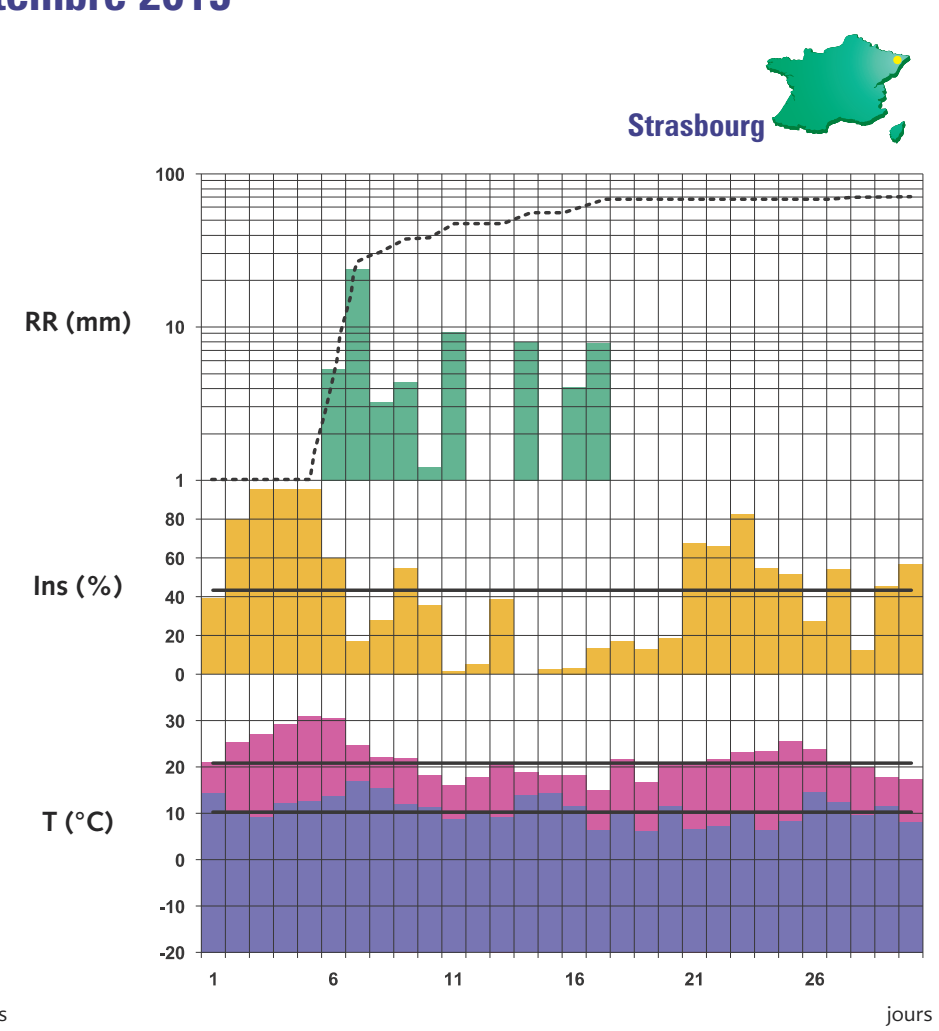

Total mensuel des précipitations : 1,1 fois la normale

Fraction d'insolation moyenne : normale

Température moyenne : $>0,6^{\circ} \mathrm{C}$ à la normale
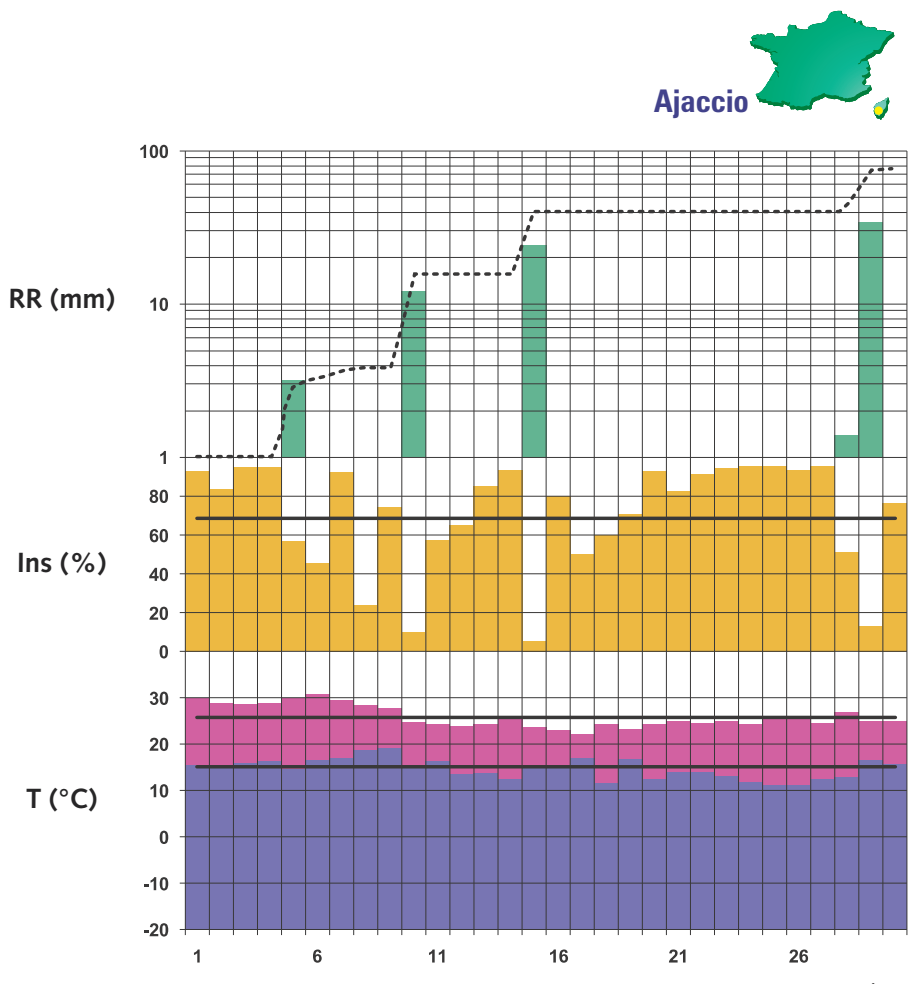

Total mensuel des précipitations : 1,5 fois la normale

Fraction d'insolation moyenne : normale

Température moyenne : normale

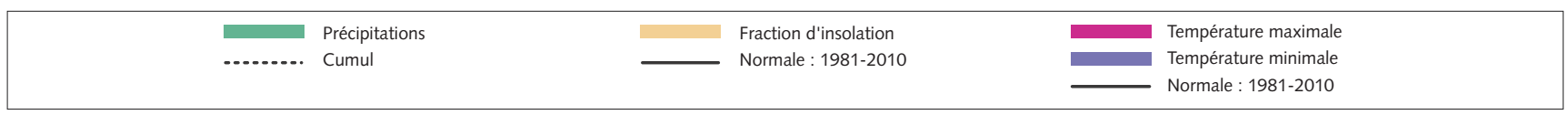

